Veritas 日 Scientia

Vol. 9. $\mathrm{N}^{\circ} 1$

Enero - Junio del 2020

ISSN Edición Online: 2617-0639

https://doi.org/10.47796/ves.v9i1.275

\title{
RECONOCIMIENTO DE LOS INGRESOS DIFERIDOS Y SU INFLUENCIA EN LA INFORMACIÓN ECONÓMICA FINANCIERA DE UNA DISTRIBUIDORA EN LA CIUDAD DE TACNA
}

\author{
RECOGNITION OF DEFERRED INCOME AND ITS INFLUENCE ON THE FINANCIAL ECONOMIC INFORMATION OF \\ A DISTRIBUTOR IN THE CITY OF TACNA \\ Juana Carolina Pacheco Fernández ${ }^{1}$ \\ Juan Guillermo Aranibar Ocola ${ }^{2}$
}

\begin{abstract}
RESUMEN
El presente trabajo de investigación analiza como los ingresos diferidos influencian en la información económica financiera de la Distribuidora Malibú SAC de la ciudad de Tacna, periodo 2014-2017. Se observó que, de la totalidad de ventas realizadas, solamente han entregado el $27,45 \%$ y quedan pendientes de entrega el $72,55 \%$ generando el problema del reconocimiento de ingresos diferidos. En la información económica financiera la mayor utilidad fue en el periodo 2015 siendo S/ 21 227,56. El margen operacional en el periodo 2014 tuvo resultado negativo, mientras que en el 2015 fue S/ 31 091,72, siendo de S/ 687,42 en el 2016 y de S/ 18 896,84 en 2017. Los márgenes brutos no mantienen una línea ascendente debido a la diferencia entre ingresos declarados y contabilizados.
\end{abstract}

Palabras Clave: Ingresos diferidos, rentabilidad.

\begin{abstract}
This research work analyzes how deferred income influences the financial and economic information of the Distribuidora Malibú SAC in the city of Tacna, period 2014 - 2017. It was observed that, of all sales made, only 27,45 have been delivered $\%$ and $72,55 \%$ are pending delivery, generating the problem of recognition of deferred income. In financial and economic information, the highest profit
\end{abstract}

\footnotetext{
${ }^{1}$ Magister en Contabilidad, Tributación y Auditoría. Asistente Administrativo del Instituto de Informática y Telecomunicaciones de la UNJBG Tacna-Perú. Carolinapf_2009@hotmail.com, ORCID: 0000-0001-6331-8516

2 Especialista en gestión Pública, Magíster en Contabilidad con mención en Auditoría, Doctorado en Ciencias Contables. jugaranibar@upt.edu.pe, jaranibaro@hotmail.com. ORCID:0000-0001-6850-5759
} 
was in the period 2015 , being $S / 21227,56$. The operating margin in the period 2014 had a negative result, while in 2015 it was S / 31 091,72, being $S / 687,42$ in 2016 and S / 18 896,84 in 2017. The gross margin does not maintain an ascending line due to the difference between declared and accounted income.

Keywords: Deferred income, profitability.

\section{INTRODUCCIÓN}

El problema planteado es respecto al reconocimiento de los ingresos diferidos que se viene presentando en gran cantidad de empresas que generalmente son medianas y grandes que no aplican correctamente el reconocimiento de sus ingresos diferidos por falta de conocimientos y de capacitación del personal, ocasionando que, la información presentada en sus estados financieros no sea confiable ni real. La información económica financiera se prepara y formula de acuerdo con los principios contables, las doctrinas y las normas legales vigentes, de modo que esta información es el resultado final del proceso contable y representa la situación en la que se encuentra la empresa en un período determinado. De la Cruz, concluye que es "importante llevar un buen control del registro de los ingresos y gastos diferidos por periodo" (De la Cruz, 2017, p. 49). El reconocimiento de los ingresos ordinarios según el método de lo percibido, debe incluir los contratos con cláusulas que deben respetar todas las partes (Montenegro, 2017, p. 52). Una de las principales ventajas de la aplicación del principio de devengo es que la empresa puede contar con liquidez para amortizar sus obligaciones financieras y fiscales (López, 2016, p. 116). Las regulaciones impositivas basadas en la Ley del Impuesto a la Renta, indica que los ingresos de la tercera categoría (ingresos del negocio) se considerarán producidos en el año comercial en que se devengan. (Silvestre, 2017, p.68). Los análisis de los estados financieros en la toma de decisiones de las empresas comerciales en la Provincia de Tacna, no es óptima (Vásquez, 2011, pp. 289-290). "Se reconoce un ingreso en el estado de resultados cuando ha surgido un incremento en los beneficios económicos futuros, relacionado con un incremento en los activos o un decremento en los pasivos, y además el importe del ingreso puede medirse con fiabilidad" (MEF, 2014, p. 24). "Si la información financiera ha de ser útil, debe ser relevante y representar fielmente lo que pretende representar. La utilidad de la información financiera se mejora si es comparable, verificable, oportuna y comprensible" (Información Financiera, 2014, p. 12). El margen bruto Barco (2009), lo define como: "La utilidad bruta sobre las ventas netas." Acerca del margen operacional, Restrepo (2017), define este indicador como: "La relación entre la utilidad operacional y las ventas totales (ingresos operacionales)" y el margen neto Noriega (2003), lo define como: "Todas las fuentes de ingresos menos el costo de los fondos y gastos operativos" (Noriega, 2003, p. 305).

\section{OBJETIVO}

Identificar la influencia del reconocimiento de los ingresos diferidos en la información económica financiera de la Distribuidora Malibú SAC, de la ciudad de Tacna, periodo 2014 2017. 


\section{METODOLOGÍA}

Investigación básica. El nivel de investigación es descriptivo. La Distribuidora Malibú S.A.C. es una empresa que comercializa ladrillos de arcilla en la ciudad de Tacna, llo y Moquegua para clientes como empresas privadas, públicas y público en general. La población está conformada por el análisis de datos de 48 meses correspondiente a cuatro ejercicios consecutivos 2014, 2015, 2016 y 2017. Se consideró al 100\% de la documentación existente.

\section{RESULTADOS}

De las ventas realizadas, se observa que en los periodos 2014 - 2017, solamente los clientes han recogido una parte de sus compras. Así tenemos que en el año 2017 la cantidad pendiente fue de 2921062 ladrillos, siendo un equivalente de S/ 1969 957,79. Debido a la magnitud de este problema, que los clientes no recojan el total de su compra, ocasiona que año tras año los ingresos diferidos vayan en aumento.

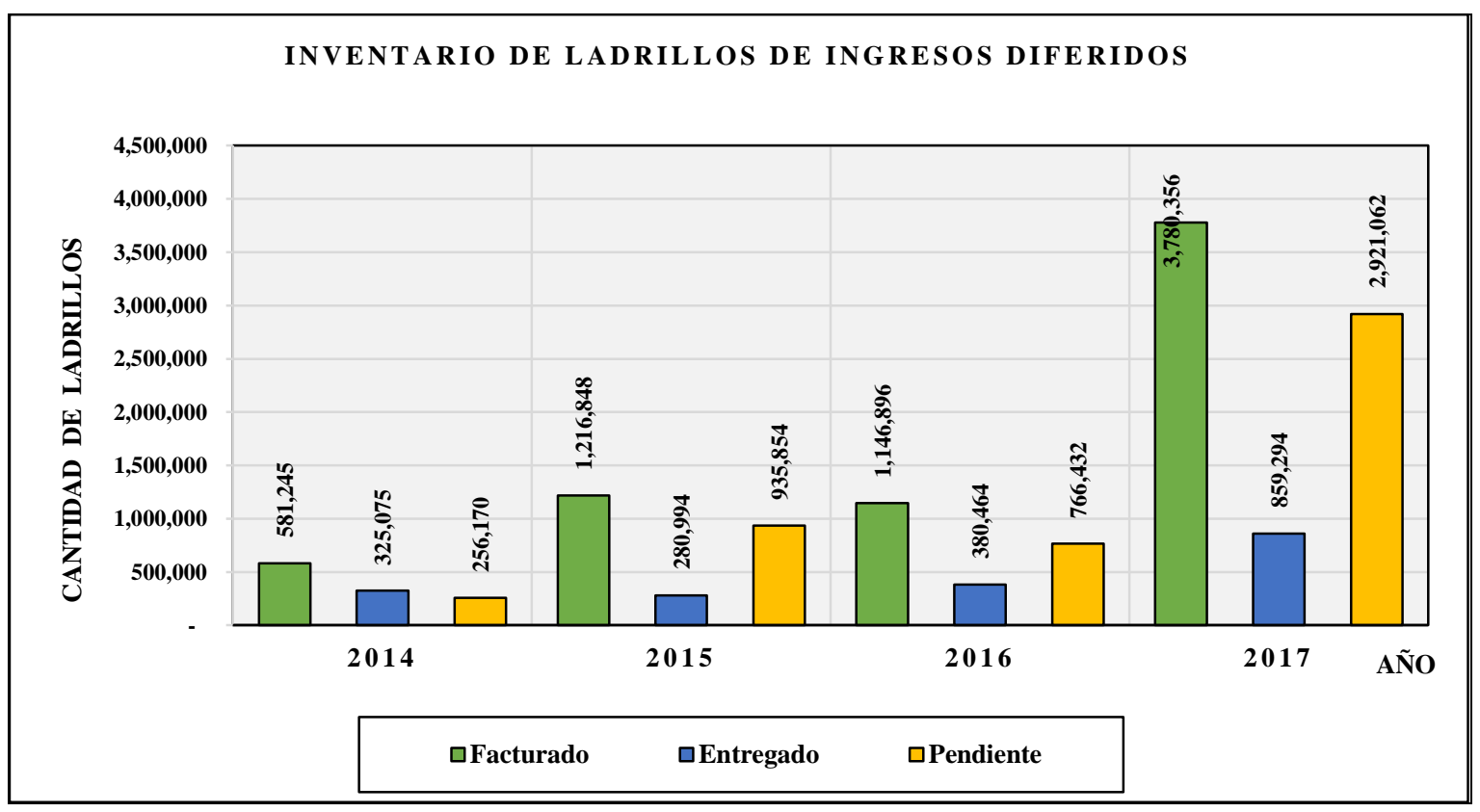

Figura 1 Inventario de ladrillos de ingresos diferidos 2014-2017

Se puede observar la tendencia a través de los años, en los cuales siempre ha ido en incremento, (Fig. 2). En el mes de mayo 2017 registró su mayor importe siendo S/ 354 592,41. Como se puede observar desde el año 2014 ha aumentado en un 215,55\%, sin embargo, el tope más alto que ha tenido ha sido en el año 2017 siendo de S/ 1969 957,84. 


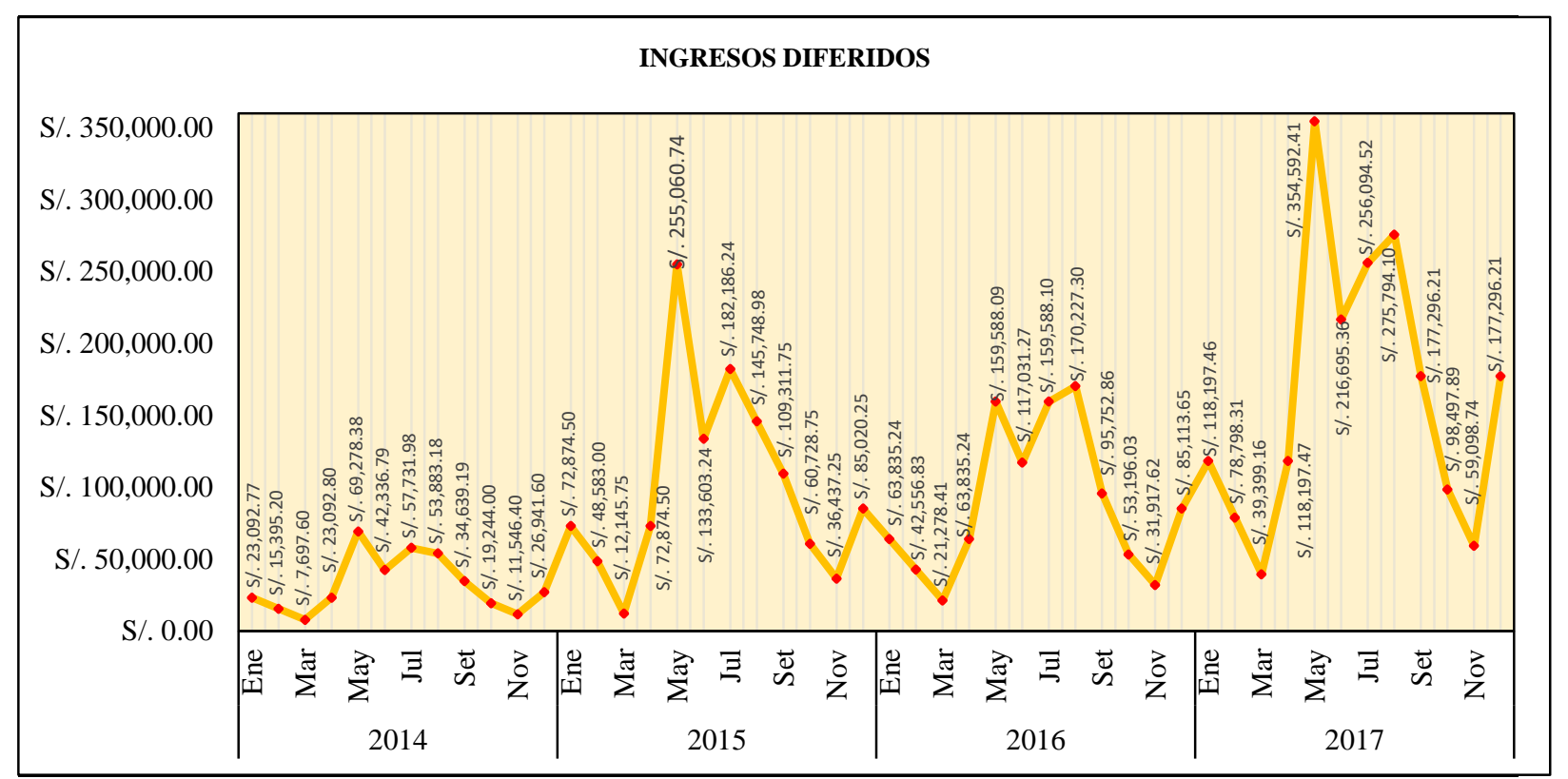

Figura 2 Ingresos diferidos 2014-2017

Referente a las mercaderías los datos fueron recabados del inventario al cierre de cada año, se puede observar una tendencia variable debido al problema de origen que son los ingresos diferidos, así se tiene que en el año 2015 se registró el importe más alto equivalente a S/ 176 724,80, mientras que en el año 2017 se redujo la cantidad de mercaderías a S/ 45 267,60. Observándose que el nivel de stock ha disminuido significativamente en los periodos 20162017 para lo cual la empresa deberá establecer los correctivos necesarios (Fig. 3).

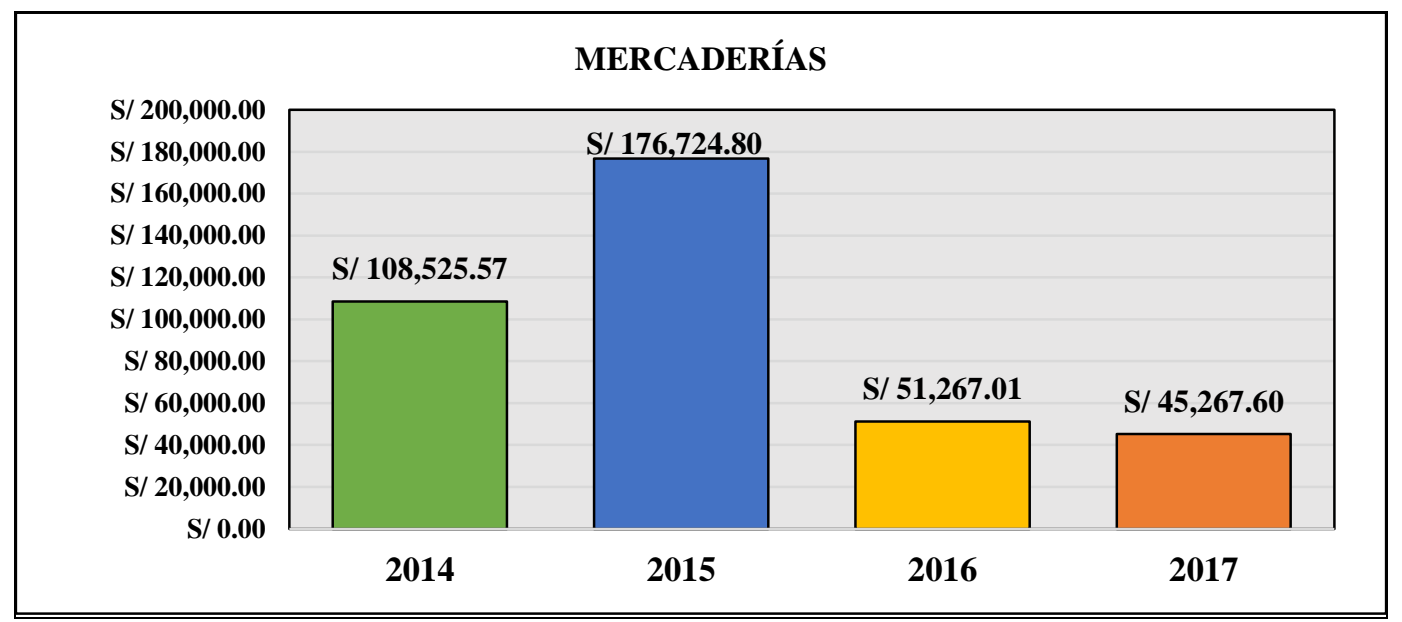

Figura 3 Mercaderías del periodo 2014-2017

Respecto a las ratios de rentabilidad (Fig. 4), se puede observar que el indicador de margen bruto, en los periodos de estudio ha tenido un resultado favorable, ya que la empresa cubre su costo de adquisición, así se tiene que en el año 2015 se obtuvo un margen bruto de 12,69\%, siendo el más alto, específicamente en el mes de marzo. Los indicadores positivos reflejan que 
la empresa cuenta con un posicionamiento en el mercado, lo cual se demuestra con las ventas alcanzadas.

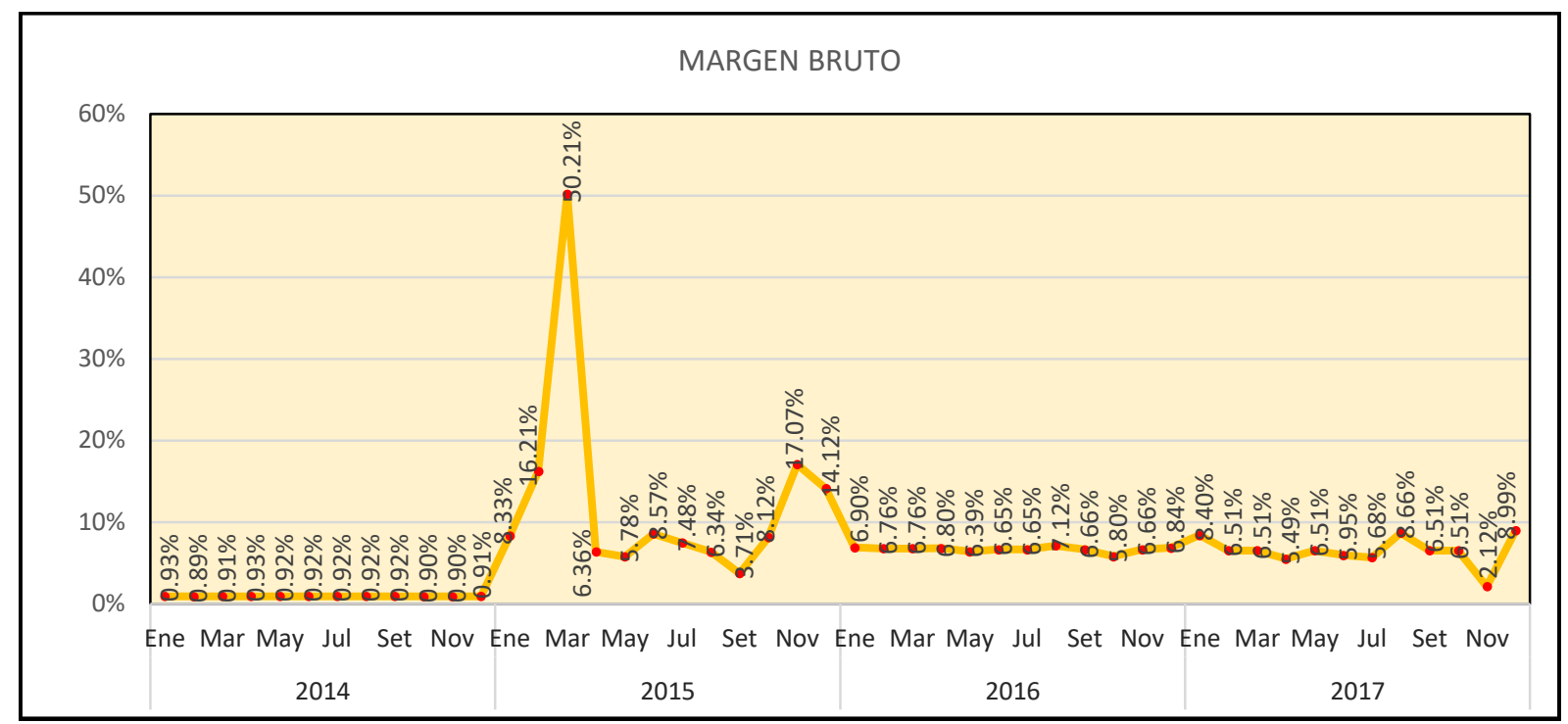

Figura 4 Margen bruto 2014-2017

Las utilidades brutas obtenidas en los años de estudio han sido aceptables, se tiene que en el año 2014 hay una mínima utilidad bruta de S/ 3 531,73, en el 2015 la utilidad bruta fue de S/ 154 163,97, en el periodo 2016 disminuyó a S/ 70 830,09 y finalmente en el año 2017 nuevamente incrementó a S/ 127 795,34. Siendo el año 2015 el de mayor importe registrado. Estos resultados favorables, se deben a que la Distribuidora Malibú SAC, es la empresa autorizada por la casa matriz, para comercializar su producto a clientes finales (Fig. 5).

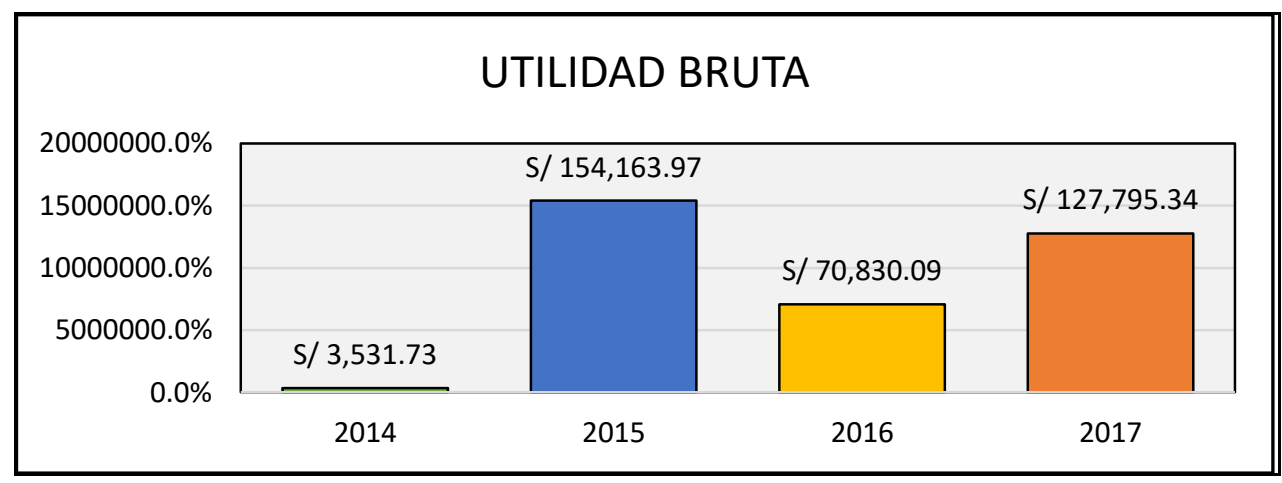

Figura 5 Utilidad bruta de los periodos 2014-2017

En relación al ratio de rentabilidad del margen operacional durante el año 2014 sus resultados fueron negativos, en el año 2015 el margen operacional se incrementó a 2,56\%, obteniendo en el mes de marzo el mayor porcentaje registrado de 15,75\%; durante el periodo 2016 disminuyó a 0,06\%; y en el periodo 2017 ascendió a 0,96\%, para lo cual es necesario establecer los procedimientos correctivos que permitan mejorar este indicador, como es reducir los gastos operativos, para tener resultados mucho más razonables (Fig. 6). 


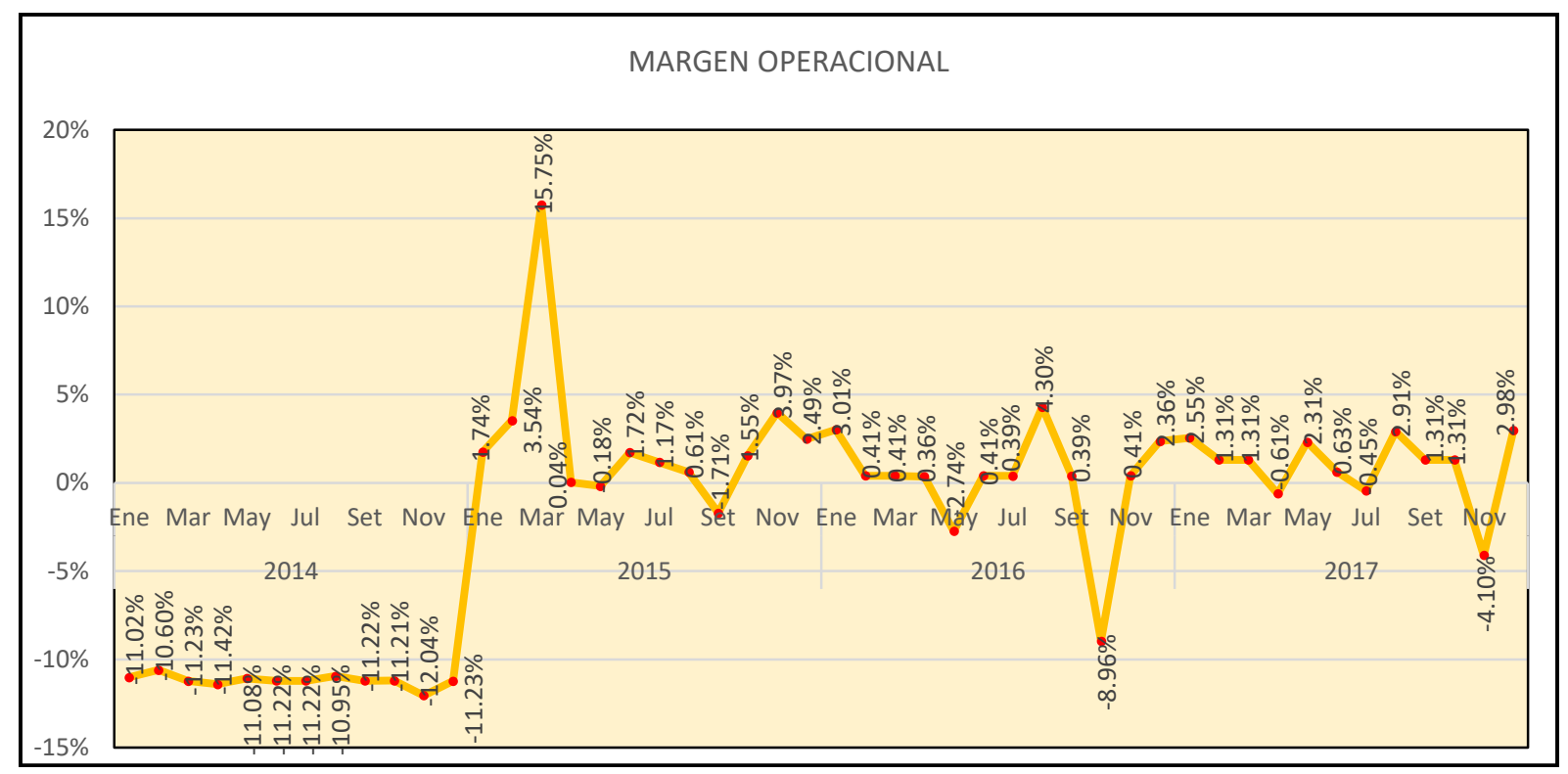

Figura 6 Margen operacional 2014-2017

La utilidad operativa generada por los ingresos diferidos (Fig. 7), ha sido positiva a partir del año 2015, siendo su tope más alto precisamente ese año con S/ 31 091,72. Cabe resaltar que en el año 2016 la utilidad operativa obtenida fue mínima de $S / 18896,84$. Esto se debe a los altos gastos operativos que incurre la empresa, sobre todo los gastos de venta, los cuales deben ser analizados con el fin de minimizarlos.

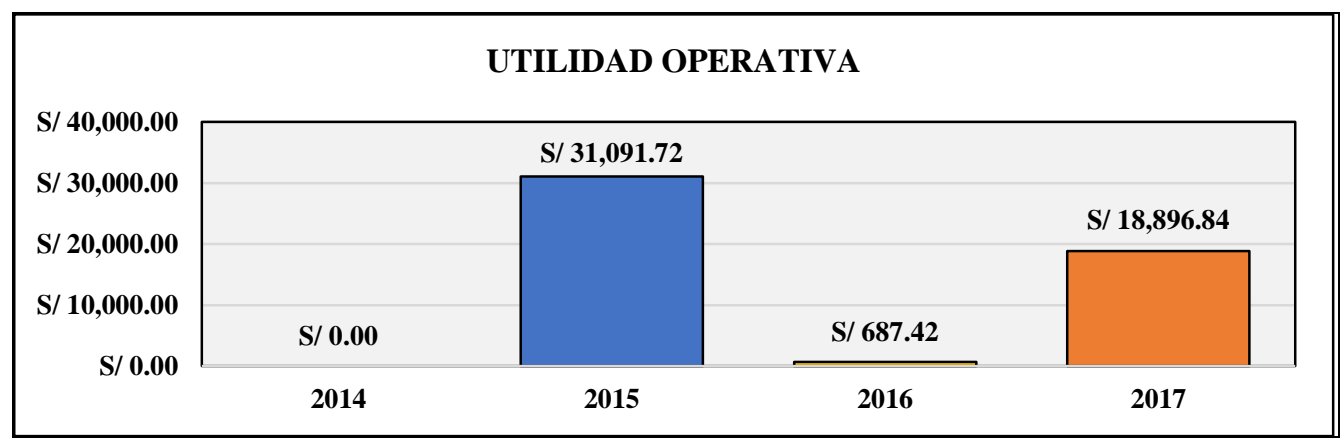

Figura 7 Utilidad operativa de los periodos 2014-2017

Finalmente, según el indicador de rentabilidad, se puede observar que se ha tenido un margen favorable en los años de estudio, siendo el indicador más alto el del año 2015 con 1,75\%, registrando en el mes de marzo el mayor indicador con 13,36\%, mientras que en el año 2017 el indicador fue $0,65 \%$, siendo en el mes de noviembre el menor obtenido de $-4,21 \%$; sin embargo los indicadores obtenidos son favorables en los cuatro años de estudio lo cual demuestra que es una empresa rentable ya que cubre sus costos y gastos, pero se podría optimizar el indicador realizando una análisis de gastos, sobretodo el costo de adquisición y los gastos de ventas (Fig. 8). 


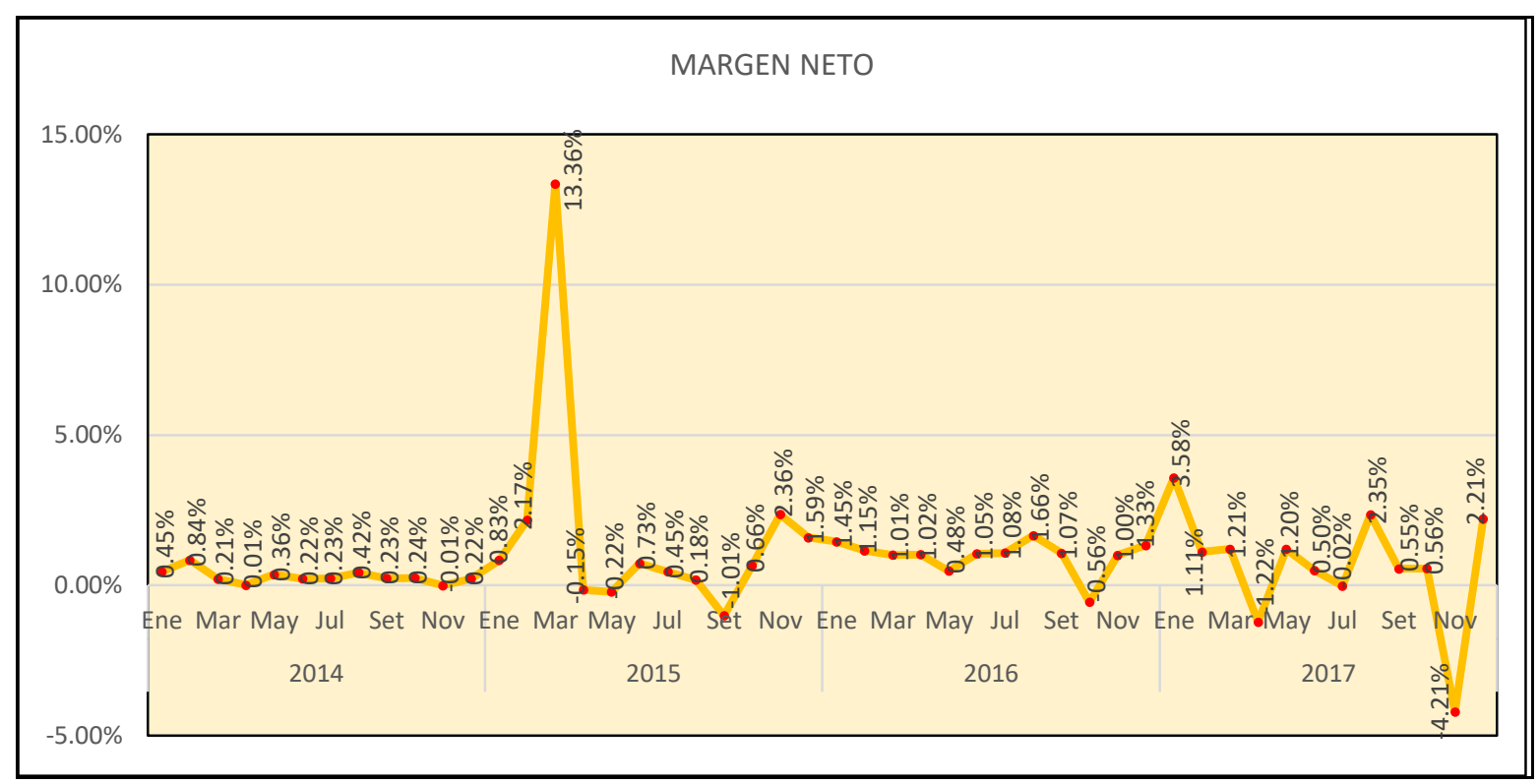

Figura 8 Margen neto 2014-2017

En lo que respecta a la utilidad neta (Fig. 9) generada por los ingresos diferidos en el periodo 2014 fue de S/ 1 131,01, en el periodo 2015 aumento significativamente a S/ 21 227,56, en el año 2016 disminuyó a S/ 10 456,80 y en el año 2017 se mostró un ligero incremento a S/ 12 895,31 . Apreciándose que la empresa ha ido incrementando su utilidad generada por los ingresos diferidos en el periodo 2015 y fue disminuyendo en los periodos 2016 y 2017, sin embargo, la empresa cuenta con una utilidad neta favorable, cabe recalcar que se puede mejorar ya que con un adecuado control de gastos y un ordenando el proceso de venta mediante la implementación del Manual propuesto, los resultados serán más óptimos.

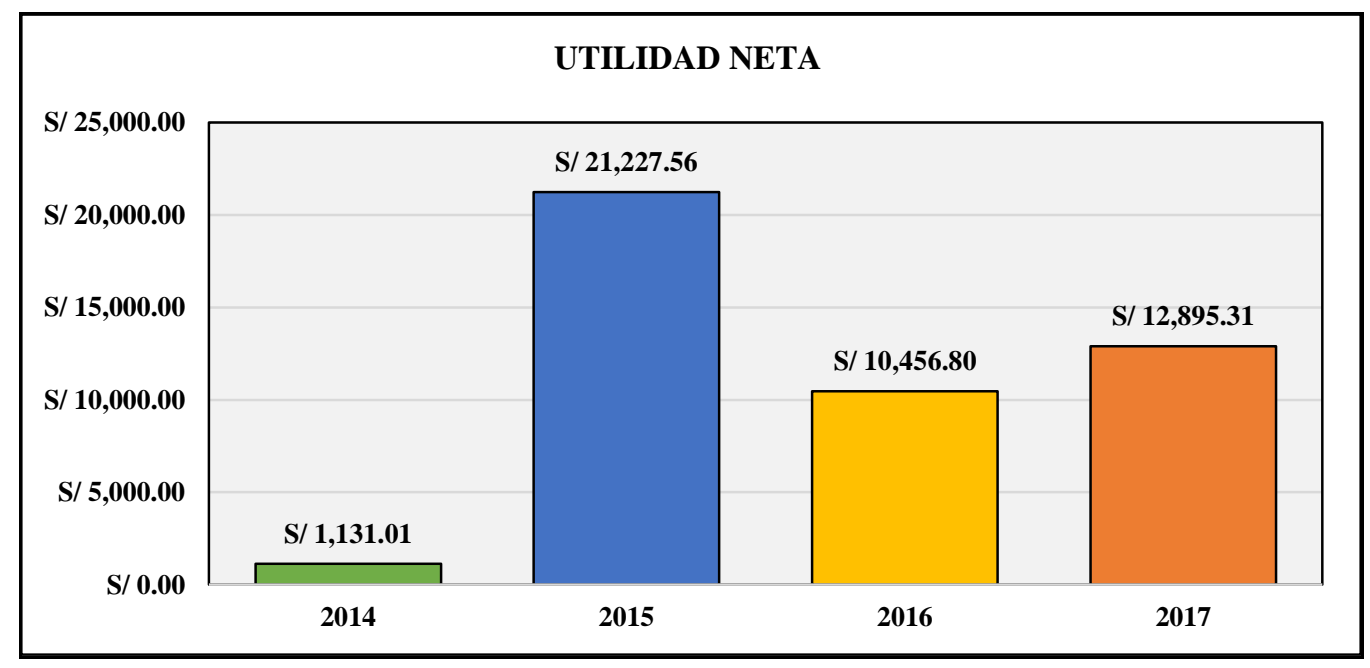

Figura 9 Utilidad neta de los periodos 2014-2017 
Entre el reconocimiento de los ingresos diferidos existe una correlación directamente proporcional positiva muy fuerte (coeficiente Rho de Spearman $=0,901$ ) con la Información económica financiera de la Distribuidora Malibú SAC de la ciudad de Tacna, periodo 2014 2017.

\begin{tabular}{lllrr}
\hline & & & $\begin{array}{c}\text { Información } \\
\text { económica } \\
\text { financiera }\end{array}$ \\
\hline $\begin{array}{l}\text { Rho de } \\
\text { Spearman }\end{array}$ & Reconocimiento & Coeficiente de correlación & 1,000 & 0,901 \\
& de ingresos & Sig. (bilateral) &. & 0,000 \\
& diferidos & $\mathrm{N}$ & 48 & 48 \\
& Información & Coeficiente de correlación & 0,901 & 1,000 \\
& económica & Sig. (bilateral) & 0,000 &. \\
& financiera & $\mathrm{N}$ & 48 & 48 \\
\hline
\end{tabular}

\section{DISCUSIÓN}

Se propone reducir el reconocimiento de los ingresos diferidos, a través de la implementación de un Manual Interno del Proceso de Venta, teniendo como regla que la venta se efectúe de manera inmediata o como plazo máximo de 3 meses para el posterior despacho del producto, es decir que se realice la respectiva entrega del producto al cliente. Con la implementación de este Manual, se proyecta que los ingresos diferidos disminuyan en un $80 \%$, debido a que será responsabilidad directa del vendedor realizar un seguimiento constante a su cliente, para el pago efectivo de su comisión. Mientras que para los años anteriores se propone realizar una revisión minuciosa de la relación de facturas y boletas pendientes de entrega, mediante un cruce con las Guías de Salida (Internas y de Remisión), publicar un aviso en el periódico local de la ciudad correspondiente, tres veces por semana por un plazo de seis meses; dirigido a todos los clientes que tienen un saldo pendiente por recoger de años anteriores, estableciendo que puedan acercarse a las oficinas administrativas para realizar el trámite correspondiente caso contrario se anulará la venta, sin opción a reclamo. Si el cliente pasado los tres meses, no se apersona a las oficinas, para coordinar el despacho de su producto, perderá todos los derechos sobre su compra. Posteriormente, en la contabilidad, por los años de antigüedad de los ingresos diferidos se reconocerá como venta, pagando el impuesto a la renta que implique, no obstante, se considerarán como diferidas los pendientes de entrega de los últimos 3 años. Con esta aplicación se busca, sincerar la información económica financiera, para una correcta toma de decisiones de los usuarios, mediante una buena aplicación de las normas para los ingresos diferidos, el cual tendrá un respectivo control de los despachos pendientes, y a la vez contribuir con el Estado mediante el pago del impuesto a la renta en el momento oportuno, y no generar implicancias tributarias. Frente a un mercado competitivo, la empresa busca introducir estrategias de marketing que le permita obtener mayor participación del mismo; es así que, ejecuta prácticas comerciales como son los descuentos y promociones, que se implementan como impulsor de alcanzar metas comerciales y a establecer hábitos en beneficio del consumidor. Los descuentos y promociones en todos los casos cumplen con los principios de Legalidad, Libre Competencia, Neutralidad, Libre Elección, No Discriminación e Igualdad ante la Ley. La empresa trabaja con sub distribuidores bajo condiciones fijada en contratos comerciales, con lo que se establece 
un padrón de clientes clasificados con este tipo. Los descuentos y promociones serán aplicados con base de las listas de precios aprobados por la administración. Las promociones ofertadas por la empresa serán estacionales; estas guardaran los debidos términos de cantidad y plazo ofertado, el cual será publicado oportunamente para su publicidad. En el mercado laboral del rubro comercial de materiales de construcción, se trabaja bajo la modalidad de comisiones y bonificaciones adicionales a sueldos básicos de los agentes de ventas. La empresa buscará brindar un ambiente positivo desde una perspectiva económica y seguro, mediante incentivos que reflejan el reconocimiento merecido por parte del personal de ventas. La administración efectuará rotación de personal de ventas periódicamente según programa recomendado por Jefatura de Ventas para generar un mayor dinamismo e interacción con el cliente. Las ventas corporativas, que se resuelven mediante contratos especiales, serán administradas exclusivamente por Jefatura de Ventas. Los cálculos de los incentivos se realizarán en períodos contemplado entre el día 29 del primer mes y el 28 del mes siguiente, con el fin de dinamizar el cierre de planillas. La empresa designará el factor correspondiente a cada punto de venta, que será multiplicado por el tonelaje vendido total, siendo el siguiente, se considerará el pago de comisión al vendedor cuando se cumplan los siguientes requisitos: a. El comprobante de pago este cancelado en su totalidad y $b$. El comprobante haya sido atendido al $100 \%$.

La empresa deberá aplicar adecuada y oportunamente las Normas Internacionales de Contabilidad, así como las Normas Internacionales de Información Financiera, ya que son guías fundamentales para elaborar la información económica financiera, teniendo como resultado una información confiable y certera, que evitará incurrir en contingencias tributarias. A través de la gerencia se debe llegar a un nuevo acuerdo comercial con el proveedor para la distribución de sus productos, estableciendo un precio acorde con la realidad teniendo en cuenta la fuerte competencia en el mercado, y que la empresa es exclusiva de su marca, con la finalidad de aumentar el indicador del margen bruto.

Se debe realizar un análisis detallado de los gastos operativos que incurre la Distribuidora Malibú SAC, específicamente de los gastos de ventas, evaluando la planilla de sueldos, ya que estos gastos se están ejecutando en el periodo indicado, pero los ingresos no se están reconociendo hasta que se entregue el producto al cliente, para lo cual se deberá culminar el proceso de venta. A través de la implementación del Manual del Proceso de Venta se podrá establecer una política, que realmente es necesaria para la empresa, ya que no hay un control sobre estos ingresos diferidos, y en lugar que disminuyan va en aumento. Al tener un control sobre ellos, los indicadores mejorarían, ya que estos importes se podrán reconocer como un ingreso devengado dentro del periodo ejecutado y por lo tanto representará mayor rentabilidad. Es por ello que se propone la implementación de este Manual, con la finalidad de minimizar esta problemática ya que se ejecutaría el problema de raíz que es la culminación del proceso de venta, tanto las posteriores como las ventas de años anteriores.

\section{REFERENCIAS BIBLIOGRÁFICAS}

Barco, D. (2009), Análisis de la Situación de la Empresa Ratios de Rentabilidad. Recuperado.http //www.aempresarial.com/web/revitem/2_9090_70148.pdf

Consejo de Normas Internacionales de Contabilidad (2014). Marco conceptual para la Información Financiera. https://www.mef.gob.pe/contenidos/conta_publ/ 
con_nor_co/vigentes/NIIF/marco_conceptual_financiera2014.pdf.

Consejo Técnico de la Contaduría Pública - Organismo Adscrito al Ministerio de Comercio, Industria y Turismo de Colombia (2016), Ingresos Recibidos por Anticipado. Obtenido de: http://www.incp.org.co/Site/2016/info/archivos/ Concepto-511-de-21-Junio-2016.pdf

De la Cruz, J., Mego, M. y Toribio, M., (2017), El principio contable de devengado y su influencia en los estados financieros de la empresa consorcio comercial universal s.a. Con sede en san juan de Miraflores año 2016. (Tesis de Pregrado, Universidad Peruana de las Américas, Lima, Perú)

Herrera, A., Betancourt, V., Herrera, A., Vega, S. y Vivanco, E. (2016). Razones financieras de liquidez en la gestión empresarial para toma de decisiones. QUIPUKAMAYOC Revista de la Facultad de Ciencias Contables Vol. 24 № 46 pp. 151-160 (2016) UNMSM, Lima - Perú ISSN: 1560-9103 (versión impresa) / ISSN: 1609-8196 (versión electrónica).

López, J. (2016) El principio del devengado de los ingresos y su afectación para la determinación de los pagos a cuenta de la actividad inmobiliaria del régimen general del impuesto a la renta caso empresa roca inmobiliaria y construcción E.I.R.L. Arequipa 2015. (Tesis de Pregrado, Universidad Nacional de San Agustín, Arequipa, Perú)

Marco Conceptual para la Información Financiera - MEF. Información recuperada de: https://www.mef.gob.pe/contenidos/conta_publ/con_nor_co/vigentes/niif/marco_conceptua I_financiera2014.pdf.

Montenegro, B. y Melgarejo, C. (2017) Reconocimiento de ingresos y costos provenientes de contratos de construcción y el impacto en la utilidad de la empresa Edificasa Perú S.A.C. del año 2016. (Tesis de Pregrado, Universidad Tecnológica del Perú, Lima, Perú)

NIC 1 (2006). Presentación de estados financieros.

NIC 18 (2006). Ingresos de actividades ordinarias.

Noriega, H. (2003). El logro de equilibrio en las microfinanzas. Guía práctica para movilizar ahorros. Recuperado de: https://cdn.websiteeditor.net/a448ed723b1748cba5c31eeb5213a66e/files/uploaded/04\%2520ESPub\%2520USAI D.gov-pnacu034\%2520ES\%25202000.pdf.

Restrepo, L. (10 de Octubre de 2017). Principales indicadores de rentabilidad empresarial. Recuperado de https //mdc.org.co/principales-indicadores-de-rentabilidad-empresarial

Silvestre, S., Arriaran, R. y Poma, E. (2017) "NIC 18 y el reconocimiento de ingresos por la venta de bienes y su incidencia en los estados financieros de la empresa Enviroequip S.A.C." (Tesis de pregrado) Universidad Peruana De Las Américas. Lima. Perú.

Vásquez, L. (2011) La incidencia del análisis de los estados financieros en la toma de decisiones de las empresas comerciales en la Provincia de Tacna (Tesis de maestría) Universidad Nacional Jorge Basadre Grohmann. Tacna. Perú. 